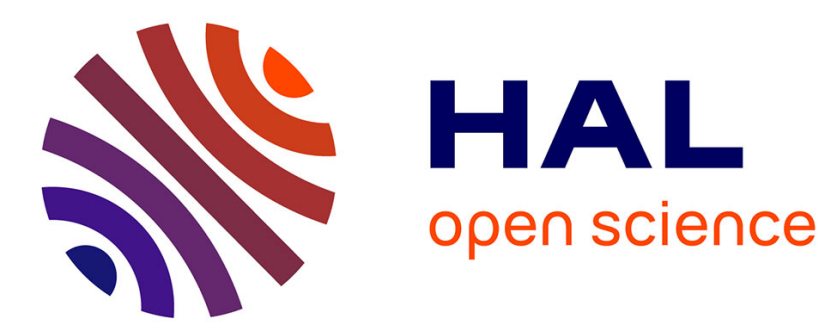

\title{
On seizure semiology
}

Aileen Mcgonigal, Fabrice Bartolomei, Patrick Chauvel

\section{To cite this version:}

Aileen Mcgonigal, Fabrice Bartolomei, Patrick Chauvel. On seizure semiology. Epilepsia, 2021, 62

(9), pp.2019-2035. 10.1111/epi.16994 . hal-03522906

\section{HAL Id: hal-03522906 \\ https://hal.science/hal-03522906}

Submitted on 12 Jan 2022

HAL is a multi-disciplinary open access archive for the deposit and dissemination of scientific research documents, whether they are published or not. The documents may come from teaching and research institutions in France or abroad, or from public or private research centers.
L'archive ouverte pluridisciplinaire HAL, est destinée au dépôt et à la diffusion de documents scientifiques de niveau recherche, publiés ou non, émanant des établissements d'enseignement et de recherche français ou étrangers, des laboratoires publics ou privés. 
McGonigal A, Bartolomei F, Chauvel P. On seizure semiology. Epilepsia. Published online July 2021

\section{On seizure semiology}

Aileen McGonigal ${ }^{1,2},{ }^{*}$ Fabrice Bartolomei $^{1,2}$, *Patrick Chauvel ${ }^{3}$

${ }^{1}$ Aix Marseille Univ, Inserm, INS, Institut de Neurosciences des Systèmes, Marseille, France

${ }^{2}$ APHM, Timone Hospital, Clinical Neurophysiology, Marseille, France

${ }^{3}$ Department of Neurology, University of Pittsburgh Medical Center, Pittsburgh PA, USA

*These authors equally contributed

Corresponding author: Dr Aileen McGonigal

APHM, Timone Hospital, Clinical Neurophysiology, Marseille, France

Email: aileen.mcgonigal@univ-amu.fr

Tel. +33491384995

Fax. +33491385826

Key words: neural networks, epilepsy, behavior, semiology, seizure classification 
McGonigal A, Bartolomei F, Chauvel P. On seizure semiology. Epilepsia. Published online July 2021

\section{Summary}

The clinical expression of seizures represents the main symptomatic burden of epilepsy.

Neural mechanisms of semiological production in epilepsy, especially for complex behaviors, remain poorly known. In a framework of epilepsy as a network rather than a focal disorder, we can think of semiology as being dynamically produced by a set of interconnected structures, in which specific rhythmic interactions, and not just anatomical localization, are likely to play an important part in clinical expression. This requires a paradigm shift in how we think about seizure organization, including from a presurgical evaluation perspective. Semiology is a key data source, albeit with significant methodological challenges for its use in research, including observer bias and choice of semiologic categories. Better understanding of semiologic categorization and pathophysiological correlates is relevant to seizure classification systems. Advances in knowledge of neural mechanisms as well as anatomic correlates of different semiological patterns could help improve knowledge of epilepsy networks and potentially contribute to therapeutic innovations.

Key words: neural networks, epilepsy, behavior, semiology, seizure classification 
McGonigal A, Bartolomei F, Chauvel P. On seizure semiology. Epilepsia. Published online July 2021

\section{Introduction}

The French word "sémiologie" (from the Greek semeîon meaning sign) was originally used as a general term in medicine from the $18^{\text {th }}$ century onwards to express the symptoms and signs associated with disease, and became adopted in medical writings elsewhere in Europe throughout the $19^{\text {th }}$ century ${ }^{1}$. The term has come to be employed internationally in its English form particularly in the context of epilepsy, meaning the pattern of symptoms and signs produced during seizures.

To state the obvious, epileptic seizures are made manifest through their tangible semiological expression, which is the cardinal feature of epilepsy: "disease is only revealed by the symptoms it produces" ${ }^{2}$. Success or failure of medical and surgical treatments of epilepsy are judged on their ability to suppress the clinical expression of seizures ${ }^{3}$. Seizure semiology was the original data source in the ancient study of epilepsy: descriptions of different patterns exist from as early as 2000B.C., including motor signs and their corporeal localization and lateralization, alteration of consciousness, somatosensory features and autonomic changes, and attempts to hypothesize the origins of these $\mathrm{e}^{4}$. From the end of the $19^{\text {th }}$ century into the $20^{\text {th }}$ century, in refining knowledge of the cerebral basis of epilepsy, the value of semiological analysis was understood by many investigators: notable landmarks include the work of John Hughlings Jackson (correlation of seizure semiology with neuroanatomical findings including post-mortem investigation) ${ }^{5}$, Wilder Penfield (study of signs triggered by intraoperative cortical stimulation studies) ${ }^{6}$, Henri Gastaut (categorization of semiology and correlations with surface electroencephalography (EEG) ${ }^{7}$ and Jean Bancaud, in collaboration with Jean Talairach (anatomical electroclinical correlations of seizures recorded on stereoelectroencephalography $(\mathrm{SEEG})^{8,9}$. The work of Henri Gastaut 
merits special mention, as amongst many other contributions his detailed observations and precise definition ${ }^{10}$ of semiological features and electroclinical correlations led to the first proposed classification of seizure types in the mid 1960's. Gastaut's emphasis on specific semiologic subtypes has remained a key component throughout subsequent revisions of the ILAE seizure classification until the present ${ }^{11-13}$.

While seizure semiology is the tangible expression of epilepsy, and a key element in epilepsy diagnosis, classification and localization, it can paradoxically appear an elusive and somewhat challenging entry point to understanding seizure organization, especially where correlation between semiology and EEG is not evident. In epileptic seizures, congruence can be observed in terms of the grouping and the evolution of clinical signs: semiological expression does not occur haphazardly but follows a sequence that is related to the cerebral progression of the seizure discharge ${ }^{14}$, with the organization of semiological elements having been compared to "words in a meaningful sentence" ${ }^{15}$. We could also think of clinical seizure phenomenology as representing a specific behavioral architecture, with its own spatial and temporal dynamic ${ }^{16}$. On the other hand, while clearly linked to cerebral seizure activity, how exactly semiologic architecture maps onto cerebral dynamics remains elusive for many seizure patterns.

This article attempts to provide an overview of current understanding of semiology as a data source in epileptic seizures, with an emphasis on focal epilepsy, especially with regards to neural correlates. This is especially relevant in a context of presurgical evaluation, but also in terms of how semiology is used in classification systems, and more generally in a perspective of neuroscientific progress. 
McGonigal A, Bartolomei F, Chauvel P. On seizure semiology. Epilepsia. Published online July 2021

\section{Semiology and seizure classification systems}

Semiology is the core feature of seizure classification systems. Henri Gastaut's proposal for seizure classification ${ }^{17}$, the precursor to subsequent ILAE classification schemes, was based on a phenomenological approach, incorporating "site of origin, the extent of spread of the excessive neuronal discharge, and the consequent clinical symptomatology"7 ${ }^{\prime 7}$ Thus, from the outset clinical expression and EEG were analyzed together and assumed to be linked, indeed considered "inseparable" by Gastaut", who effectively thus put forward a form of multiscale framework implying underlying pathophysiological mechanisms. His classification underlined the importance of precise diagnosis for individual patients in terms of prognosis and treatment, as well as the need to compare data internationally in a clinical research perspective. He emphasized the likely interplay of cortical and midline subcortical structures within anatomically connected systems with regards to both seizure organization and semiological production". Indeed, he preferred the term "partial" to "focal" seizures, "in order to emphasize that the participating neural system may be distributed to a variable extent throughout a segment of the entire three-dimensional cerebral volume. It therefore cannot be represented geometrically as a locus, even less as a focus" ${ }^{\prime 7}$.

On the other hand, it was commented by Luders and colleagues that the ILAE seizure classification, developed as a direct result of Gastaut's work ${ }^{13}$, was not well adapted for use in a presurgical context, in which the zones of seizure onset, propagation and clinical expression required to be elucidated ${ }^{18}$. In this localizationist approach, anchored in a practical need to better identify and select candidates for epilepsy surgery, a specific semiological classification system ${ }^{19}$ was proposed by Luders and co-workers that aimed at addressing perceived limitations ${ }^{18}$ of the existing International League Against Epilepsy 
McGonigal A, Bartolomei F, Chauvel P. On seizure semiology. Epilepsia. Published online July 2021

(ILAE) classification scheme. Following progressive revisions of the ILAE seizure classification system up until the present ${ }^{12}$, the issue of how best to represent semiological information within a seizure classification scheme remains energetically debated within the epileptology community ${ }^{20}$.

Neural networks versus epileptic focus: relevance to semiological analysis

\section{Concept of epileptogenic networks}

When thinking about semiology and its relation to cerebral organization, the concept of the network basis of epilepsy is fundamentally different from the epileptic focus model. It has been progressively accepted by clinicians that there is much evidence in favor of epilepsy being a network disorder ${ }^{21-23}$; this idea is decades old, having been formally explored using mathematical ${ }^{24}$ and animal models ${ }^{25}$ of epilepsy from the 1970 's onwards. In a clinical context, Susan Spencer and collaborators, based on observations from depth electrode recordings and subdural grids in the 1980's and 1990's, highlighted the concept of the epilepsy network, considering this to be a "functionally and anatomically connected, bilaterally represented, set of cortical and subcortical brain structures and regions in which activity in any one part affects activity in all the others"21. Spencer linked semiological output to this network organization, pointing out that "the network as a whole is responsible for the clinical and electrographic phenomena that we associate with human seizures" 21 .

However, many years prior to this, the concept of network organization of seizures and its expression via specific semiological patterns had already begun to be investigated by Jean 
McGonigal A, Bartolomei F, Chauvel P. On seizure semiology. Epilepsia. Published online July 2021

Bancaud ${ }^{26}$ based on his observations with Jean Talairach and coworkers from the early 1960's onwards, using SEEG for presurgical epilepsy evaluation ${ }^{9}$. Bancaud and Talairach observed that seizure activity may be recorded simultaneously or near-simultaneously in distant (yet connected) structures; and that initial organization of the seizure could be more or less separate from a cerebral lesion, if present ${ }^{9,27,28}$. This framework derived from SEEG observations distinguished lesional zone (interictal slow activity), irritative zone (interictal spikes) and epileptogenic zone (initial organization of the seizure), which were linked and could overlap to a variable degree ${ }^{9,23,28}$. A key concept of the SEEG method was "anatomical electroclinical correlation", comparing semiology as it evolved with the characteristics of the signal in different anatomical locations, not only considering seizure onset but also the period of early spread of the discharge ${ }^{9,28,29}$. With the advent of digital EEG, quantification of SEEG signal allowed mathematical analysis of signals in different anatomical structures across time. SEEG studies particularly employing novel, non-linear signal analyses from the late 1990's onwards ${ }^{30,31}$ permitted the formal demonstration of specific neural networks in the genesis and propagation of seizures ${ }^{32}$. Notably, rather than "epilepsy network", the more specific term "epileptogenic network" has been proposed based on study of underlying pathophysiologic processes using brain biomarkers of epileptogenicity ${ }^{23}, 33$. SEEG studies of different seizure types and semiological patterns have highlighted the importance of temporal aspects of seizure organization, that is, concerning discharge frequency, lag and synchrony between signal in different structures (Table 1), as well as spatial (anatomical) aspects (Table 2). These studies, especially those utilizing signal analysis methods in relation to the period of clinical expression of the seizure, have suggested some putative mechanisms of semiological production. 


\section{Concept of symptomatogenic zone}

In contrast to this epileptogenic network view, which was the hallmark of the French SEEG school, the domain of correlating semiology with intracranial EEG data was subsequently developed by Luders and collaborators ${ }^{34-36}$ as well as other groups $\mathrm{s}^{37-40}$ using a different investigative method, recording from the brain using subdural grids and/or mesial temporal depth electrodes. A system of "zones" was expounded by Luders and coworkers ${ }^{27}$ that included representation of how semiological output was linked to cerebral seizure organization. However, it is important to note that the origin of the "zones" model can in fact be traced back to Bancaud as described above, who had initiated this novel framework decades earlier. Luders defined symptomatogenic zone as "the area of cortex that, when activated by an epileptiform discharge, produces the ictal symptoms"; the definition of epileptogenic zone by this school was considered pragmatically as the minimum amount of cortex that must be resected to render the patient seizure-free ${ }^{27}$. These constructs were strongly influenced by data from direct cortical stimulation studies and their clinical correlates $^{41}$, as well as study of cases becoming seizure-free following epilepsy surgery. This approach therefore tended to employ a "focus" model of epilepsy, albeit one that recognized the variable spatial extent of seizure onset as well as an anatomical separation between epileptogenic zone and symptomatogenic zone. In this framework, the relation between structures involved in seizure onset and those involved in semiological production was essentially conceptualized as a linear and mechanistic process occurring within the spatial domain and the symptomatogenic zone model did not attempt to address issues of pathophysiological mechanisms other than inferring local functional anatomical correlations. 
The fundamental difference between Luders' focal definition of the EZ, and that proposed previously by the SEEG school- which represented initial seizure organization within a set of connected structures, as well as more complex mechanisms involved in producing clinical signs- was indeed acknowledged by Luders and co-workers ${ }^{27}$. Some of these differences in focal versus network epilepsy models can be directly attributed to choice of recording method and the view thus afforded of seizure organization with regards to clinical expression $^{28}$.

\section{Network or focus model for investigating neural correlates of semiology?}

There is a somewhat contradictory and ambiguous relation between the epileptogenic network model and the epileptic focus model in clinical practice, both probably representing different aspects of reality (perhaps akin to the co-existence of wave and particle theories of light). The conceptual and scientific appeal of epilepsy networks notwithstanding, the idea of an "epileptic focus" can seem logical, intuitive and even necessary as a working model for clinicians. The focal epilepsy model seems to fit with the observed success of focal surgical resection in many cases, initiated by the earliest epilepsy surgical resections in the $19^{\text {th }}$ century $\mathrm{y}^{42}$ and reinforced following the development of widespread epilepsy surgery programs based on high surgical success rates in mesial temporal epilepsies ${ }^{43}$. Indeed, it has been commented that, in an epilepsy surgical framework, "thinking of networks then seems impractical, because resection is ultimately focal" ${ }^{\prime 4}$. However, this ambiguity may become increasingly important to resolve if progress is to be made in understanding and treating epilepsy. This seems an important goal in the light of increasing numbers of complex, often extra-temporal cases being evaluated for epilepsy presurgical evaluation ${ }^{45}$ and the 
significant proportion of patients with "focal" pharmacoresistant epilepsy who are not cured by surgery ${ }^{46}$.

When thinking about how to analyze neural correlates of seizure semiology, what is the optimal conceptual framework and methodological approach? The genesis of complex semiological patterns (e.g. gestural motor behaviors, altered consciousness, emotional signs and so on) cannot be directly attributed to electrical alterations limited to a restricted volume of cortex: by definition, the emergence of such patterns requires larger scale distributed networks to be brought into play, even if such a process may nevertheless be triggered from discharge arising within a restricted volume of cortex, according to connectivity of the epileptogenic network. It would seem impossible to adequately explain neural correlates of this type of clinical expression by the "symptomatogenic zone" model, without taking into account the role of distributed cortico-subcortical circuits; epileptogenic network-based analyses thus appear better suited to investigating these.

\section{Seizure semiology as a dynamic data source}

The semiological expression of each epileptic seizure represents a set of complex interactions between the brain (electrical discharge), body (paroxysmal physical and/or mental symptoms and signs) and the environment (effect of specific time, circumstances and interactions with people and/or objects during the seizure). This multi-level and dynamic interaction, which brings with it significant methodological challenges for analyzing semiology, could evoke the idea of "embodiment", a concept posited in the cognitive neurosciences ${ }^{47}$. Each seizure is a newly occurring event, prone to be influenced by the patient's state and environmental conditions, and yet as seizures repeat over time, a certain 
core stability of semiological expression is typically observed both within and between patients (the latter being the basis of seizure classification systems). This reproducible "choreography", which lends itself to phenomenological study, indicates that a particular configuration of neural circuitry is being brought into play each time, which may be reinforced by seizure repetition through a process of neuroplasticity ${ }^{28}$ albeit with degrees of variability related to the dynamic nature of the system. Semiology does not arise from an isolated structure but from a system defined and constrained by its connectivity, in which pathophysiological activity tends to be organized in a structured and reproducible way across seizures ${ }^{28,48}$. Considering epilepsy to be a disorder of brain networks, in which a seizure may be seen as an expression of a dynamical system ${ }^{23,49}$, seizure semiology also reflects a dynamic process operating on a different scale, characterized by both spatial and temporal aspects within the cognitive and behavioral domains ${ }^{16,50}$ (Figure 1). Attempts to understand correlations between brain activity and clinical signs during seizures must therefore take into account information collected across multiple scales ${ }^{51,52}$ : behavioral features, anatomical spread of seizure discharge and temporal organization of electrical changes (e.g., discharge frequency and synchrony between structures). Scientific study of neural correlates of semiology thus ideally requires a method allowing meaningful comparison of recorded spontaneous seizure semiology with concomitant spatiotemporal evaluation of neural activity, employing appropriate categorization of semiological features and optimal measurement of the onset and spread of seizure discharge. The biggest challenges in this context include not only issues of cerebral sampling and network analysis, but also how best to observe, describe and quantify semiological features. 
Figure 1

\begin{tabular}{|c|}
\hline $\begin{array}{l}\text { Spatial features of } \\
\text { discharge } \\
\text { e.g., anatomical localization } \\
\text { (primary cortex versus } \\
\text { associative cortex; functional } \\
\text { specificities); focal or } \\
\text { widespread onset; propagation }\end{array}$ \\
\hline $\begin{array}{l}\text { Other factors } \\
\text { modulating } \\
\text { electroclinical } \\
\text { expression }\end{array}$ \\
\hline $\begin{array}{l}\text { Bottom up effects on network, } \\
\text { e.g. sleep versus wake, arousal, } \\
\text { antiepileptic drugs; stimulation } \\
\text { versus spontaneous seizure; } \\
\text { specific neurotransmitter } \\
\text { systems, genetic profile? }\end{array}$ \\
\hline $\begin{array}{l}\text { Top down effects on network, } \\
\text { e.g interaction with } \\
\text { person/objects, emotional } \\
\text { state, specific seizure triggers } \\
\text { (e.g; noise, stress) }\end{array}$ \\
\hline
\end{tabular}
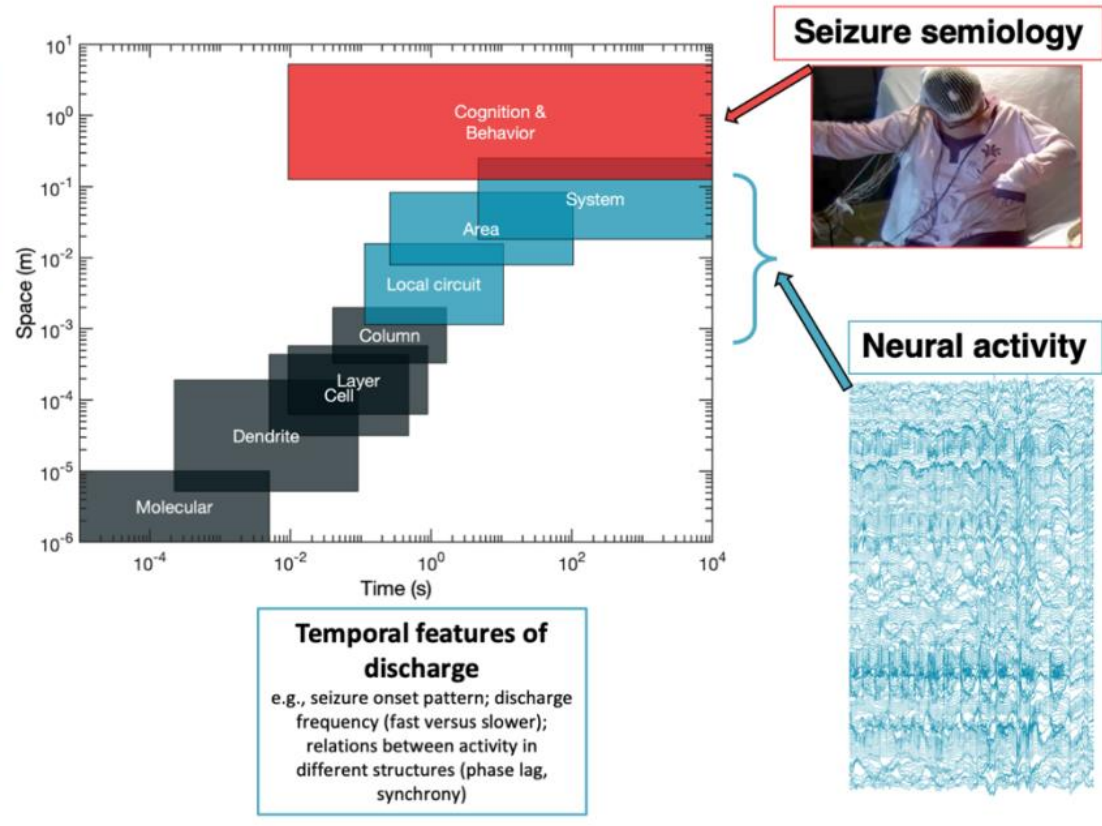

Figure 1. Use of a multi-scale framework to think about spatial and temporal features in epileptic seizure expression. The center panel illustrates temporal and spatial scales of organization in the nervous system (adapted from Lytton et $\mathrm{al}^{52}$ ). Both semiological expression and cerebral epileptic activity can be mapped onto this spatiotemporal framework. Semiology involves the higher level dimension shared by cognition and behavior, whereas cerebral electrical discharge involves the local circuit, area, and system levels. Apart from spatiotemporal features of the seizure discharge, other factors influencing electroclinical expression can be bottom-up (driven by neuronal changes) or topdown (driven by environmental factors). 


\section{What can SEEG tell us about the neural correlates of semiology?}

Stereoelectroencephalography, because of its multilobar sampling, including medial and lateral structures and sometimes also subcortical structures, has contributed important data on neural correlates of semiology that cannot be achieved using other intracranial recording techniques that share its millisecond temporal resolution. The detailed analysis of semiology as it unfolds during the whole course of the seizure with reference to sequential signal changes (anatomical electroclinical correlation) has traditionally been the foundation of the SEEG method ${ }^{9}$ and the remainder of the article will discuss SEEG data. As such, the emphasis here is on semiology in the context of focal seizures, since SEEG data has primarily come from patients undergoing presurgical evaluation for intractable focal epilepsies. There is a bidirectional relation between SEEG exploration and semiological analysis: at the individual patient level, semiology critically informs implantation strategy and is an essential component of clinical SEEG interpretation; and on the other hand, SEEG data amassed over many cases and over time informs us about neural correlates of semiology through studying electroclinical patterns that are recognizably similar across patients. Ideally each aspect should contribute to advancing the other, since better recognition of semiological patterns and their correlates should hopefully lead to refinement of implantation strategies for future patients. A main caveat here is evidently the intrinsic sampling limitations of the method with the risk of missing important information from unexplored regions ${ }^{14}$, both cortical and subcortical. Another important issue is that SEEG methodology is highly dependent on hypotheses of epilepsy organization, which strongly influence implantation strategy: erroneous hypotheses can lead to misleading or unhelpful results, if key structures are not optimally sampled. 
As knowledge and also technical capacity evolve, both within individual teams and in the wider epileptological community, implantation strategies tend to adapt over time to take this into account. A case in point is the demonstration of the role of the insula in various seizure types $^{53}$, its stimulation mapping features ${ }^{54}$ and, more recently, descriptions of larger series of insular seizures with electroclinical correlations across insular subregions $s^{55,56}$ including in terms of their connectional ${ }^{57}$ architecture. These are aspects that were unknown in the early decades of SEEG use since the insula tended to be not often explored partly because of vascular constraints. Because certain electroclinical features suggesting different insular subregions are now recognized, as well as technical improvements including vascular imaging, the indications for implanting this region have therefore changed, thus continuing to add to available electroclinical data. More generally, mean number of SEEG electrodes implanted per case has tended to increase across time, related to evolving indications for exploration and technical advances ${ }^{58}$. Investigation of semiological patterns and their correlates using SEEG has followed 2 main approaches: (1) grouping patients with a similar semiological picture or a common semiological feature and looking at cerebral correlates of seizures including temporal features of discharge (Table 1); (2) grouping patients with similar anatomical organization of the epileptogenic zone (EZ) or seizures arising from a particular brain system and looking at clinical correlates (Table 2). Single case reports can also be of interest because of specific features that can be analyzed within a single patient.

Taken together, these studies have 2 main goals: improving knowledge of anatomical correlates (with direct clinical implications for future patients); and shedding light on possible neural mechanisms underlying semiological production (which improves neuroscientific 
understanding of epilepsy). The latter objective has benefited from signal analysis studies (Table 2), especially using connectivity measures that assess codependency of signal between connected structures; see ref. ${ }^{23}$ for review. The present review focusses mainly on data from spontaneous seizures, but useful information on possible mechanisms of semiology has also been gathered from SEEG stimulation studies including signal analysis ${ }^{59,60}$.

\section{Semiological hierarchy with respect to cortical localization}

Cases in which seizure semiology is highly specific for certain spatially restricted cortical regions often involve elementary signs (such as somasthesic, visual or auditory aura, or focal clonic jerks) arising in relation to seizure activity within primary cortex. In such cases, habitual semiology can often also be reproduced by local direct cortical stimulation and indeed these were the types of presentation leading to the very early cases of epilepsy surgery ${ }^{42}$. In focal primary motor cortex seizures, clinical expression of elementary motor signs appears to depend on ictal discharge frequency as well as anatomic localization ${ }^{61}$. Some more complex signs arising from non-primary cortex can also be highly specific for anatomical location and can also often be readily reproduced by cortical stimulation (e.g. déjà vu arising from networks involving mesial temporal structures, especially entorhinal cortex ${ }^{59}$ ). In frontal lobe, stimulation of different regions of cingulate cortex has been shown to produce complex motor behaviors and emotional signs (especially laughter) ${ }^{62} 63$.

On the other hand, the majority of more complex semiological patterns involving for example gestural or hyperkinetic motor behavior, emotional change and/or altered consciousness tend to involve associative cortex, usually associated with seizure propagation within more extensive networks and more complex seizure dynamics ${ }^{50}$. It is recognized that subcortical 
mechanisms must play a role in clinical expression of many forms of focal seizure ${ }^{7,64-68}$. While subcortical structures are much less often sampled than cortical structures, growing interest has led to increasing EEG data in a clinical context from structures including the thalamus, putamen and caudate nucleus ${ }^{69,70}$. SEEG studies of synchrony during seizures have confirmed a link between degree of thalamic involvement and degree of alteration of consciousness, for example (see Table 1$)^{71}$. Recent work has highlighted the potential role of basal ganglia within a strictly topographically organized framework according to cortical localization of seizures and cortico-subcortical connectivity ${ }^{70}$.

Current concepts of brain function are based on the principle that each part of the brain has a different set of specializations and that the specializations of a brain region depend on its connections ${ }^{72}$. Regions of primary and unimodal cortex have sparse connectivity between them, in contrast to multimodal and transmodal regions of cortex, which are densely connected to allow binding of distributed information ${ }^{72}$. Following on from this distinction between unimodal and multimodal cortex, a spatial hierarchy of semiology with regards to cortical involvement of seizure organization could be posited, in which more elementary signs with highly specific relation to cortical localization are likely to involve unimodal cortex; whereas more complex signs or constellations of signs, which are relatively non-specific for individual cortical regions (e.g. hyperkinetic motor behavior ${ }^{73}$ ) or which may depend on widespread cortical involvement (e.g. altered consciousness ${ }^{66,}{ }^{71}$ ) would be related to dynamic effects involving higher-level, multi-modal or transmodal cortex and their cortical and subcortical connections.

How might gradations between these more complex expressions of semiology and the spatial hierarchy of their neural correlates be demonstrated? This would require approaches taking 
into account sufficient numbers of cases, with adequate semiological categorization and optimally sampled brain regions at seizure onset and during emergence of semiology (early spread). In reality, such approaches are always limited by clinical factors, since the minimal cerebral (SEEG) exploration for individual patients is performed based on clinical need, limiting spatial sampling within and across subjects; in addition, complex semiologies are heterogeneous and achieving series with sufficient data can be challenging. However even without signal analysis, SEEG data has shown correlation between clusters of semiological signs and co-involved brain structures in frontal epilepsy, indicating that behavioral signs and in particular motor behaviors are organized along a rostrocaudal gradient according to their complexity ${ }^{74}$, in keeping with current thinking on frontal lobe functional and anatomical hierarchy ${ }^{75}$. This type of observation confirms the interest of pursuing this line of semiological analysis even when clinical patterns are complex and brain sampling necessarily limited, since semiological output seems to be tightly linked to early cortical seizure activity despite large scale cortical and subcortical networks likely being involved ${ }^{28,76}$. On the other hand, analyzing seizure onset alone rather than incorporating anatomical structures involved in early spread does not appear to correlate as well with semiological subgroups, at least in frontal seizures ${ }^{77}$.

\section{Putative mechanisms of semiological production}

How might seizure activity interact with brain networks to produce clinical effects? Seizures may produce both abnormal inhibition and abnormal activation of involved regions and their connected structures ${ }^{65}$. Attempting to untangle the possible mechanisms of how the seizure discharge determines clinical expression is difficult, all the more so since neural mechanisms of even physiological expressions of complex brain functions remain incompletely 
understood, for example motor behavior ${ }^{78}$, emotion ${ }^{79}$ and consciousness ${ }^{80}$. Looking at expression of other neurological conditions such as movement disorders ${ }^{68}$ and parasomnias ${ }^{81}$ may help to illuminate this question. For example, stereotypies (abnormally repetitive behaviors) have been increasingly well characterized in terms of their anatomical and neurobiological substrates, involving cortico-striatal circuits that deal with learning of sequences $^{82}$. Many seizures contain repetitive movements (and indeed the whole seizure/semiological architecture could be seen as being reinforced by repetition over time), so the stereotypies model could be an interesting one for studying these mechanisms in epilepsy ${ }^{83}$.

How has SEEG analysis informed us about possible mechanisms of semiological production? A main line of research has investigated not only spatial (anatomic structures involved) but also temporal features of electrical seizure organization using signal analysis. This could be thought of as not only looking at where the network is, but how it reverberates.

Several possible mechanisms have been suggested for seizure patterns beyond the simplest clinical expressions of unimodal cortex. These are still under investigation, and it should be noted that current evidence is stronger for some patterns than others (based on numbers of cases analyzed, use of a control situation, etc. (Table 1)).

1. The concept of binding has previously been proposed as a putative mechanism for some forms of semiological production ${ }^{50,84}$, that is, functional coupling at specific (physiological-range) frequencies between connected structures, leading to a certain clinical output according to the function of the thus-activated anatomical network. This mechanism has been suggested by SEEG studies of neural correlates of dreamy state $^{85}$, ictal humming ${ }^{86}$ and oroalimentary automatisms ${ }^{87}$, which are characterized by 
correlations in specific frequency bands across co-involved structures during semiological production.

2. In seizures with altered consciousness, the degree of cortical +/- thalamic synchrony appears to correlate with degree of clinical expression, with excessive synchrony being associated with greater impairment of consciousness, across different lobar seizure localizations ${ }^{71,88,89}$.

3. In seizures with hyperkinetic motor behavior involving an emotional character (explosive onset of fear/defense behavior), sudden transient decorrelation between prefrontal cortex and amygdala at onset of clinical signs was demonstrated ${ }^{90}$. This disruption of functional connections could then result in the disruption of emotional regulation leading to the release of altered behaviour.

4. Finally, in seizures with rhythmic movements, coupling between frequency bands may reflect a temporal assembly of neural structures acting as an oscillator (rhythmic pattern generator) ${ }^{91}$. This is exemplified by an analysis of prefrontal seizures with rhythmic body rocking, in which phase lag coupling was demonstrated between gamma band activity within the epileptogenic zone and propagation regions, and the delta-band rocking frequency (quantified using video analysis) ${ }^{76}$.

These last two mechanisms could fit with and refine Tassinari's proposal of the presence of central pattern generators that would "generate rhythmic movements and express speciesspecific innate emotions" ${ }^{\prime 2}, 93$. Such central pattern generators are generally presumed to be subcortical, and possibly common to both some forms of epilepsy and some parasomnias ${ }^{94}$. However, rather than being brought into play via a non-specific top-down effect of loss of inhibition, SEEG data suggest that these would depend on interaction between cortical 
activity and subcortical circuits in a topographically organized way ${ }^{70,83}$. This means that cortical electrophysiological signatures are likely to be detectable even for those seizures in which clinical expression is strongly linked to subcortical components of the specific corticosubcortical network, as may be the case for example for ictal rocking behaviors ${ }^{91}$ and emotional expression such as defense behaviors ${ }^{90}$ and ictal aggression ${ }^{95}$.

Additional indirect evidence in favor of specific complex motor and/or emotional patterns being encoded within predominantly subcortical circuits comes from SEEG stimulation studies, in which complex semiology can be triggered with extremely short latency following train stimulation, especially in frontal seizures, with habitual semiology occurring before the cortical discharge emerges, contrary to the observed time course in the same patients' spontaneous seizures ${ }^{96}$.

\section{Methodological challenges of investigating semiology}

If progress is to be made in investigating neural correlates of semiology, it is important to be aware of certain methodological considerations (Table 3). Semiology as a data source is complex and difficult to work with for various reasons. The majority of semiological information in clinical practice of course comes in narrative form, notoriously prone to inaccuracies compared to recorded seizures ${ }^{97}$. When dealing with recorded seizures, there are various considerations concerning quality of data, including technical conditions, adequate ictal examination ${ }^{98}$ and ability of individual expert observers to perceive key signs $^{99}$ or patterns, especially for seizure types involving complex motor behavior ${ }^{100}$. A main methodological challenge relates to description and interpretation of semiological signs, and especially choice of category. This is important for accurate description and for 
meaningful comparison across series. Terms such as "hyperkinetic" and "automatism" can be useful in some circumstances but despite having been formally defined ${ }^{101}$, may prove to be unhelpful or even misleading due to lack of precision and consensus as to their meaning. One issue is in conflating an individual semiological feature with the description of the overall seizure, for example the term "hyperkinetic seizure": while this category is included in the current ILAE classification ${ }^{12}$, it does not correspond to any known localization, etiology or pathophysiological correlation. Ideally a useful semiological category should be helpful clinically, with good inter-observer and intra-observer reliability and should refer to a cohesive pattern or group of signs whose occurrence might be linked pathophysiologically. A goal for clinical research approaches and for future classification systems would be to incorporate such semiological features as knowledge progresses.

\section{Future research directions}

There is much potential for further study of semiology and its neural correlates. Epilepsy is a privileged model for studying the brain-behavior relation, given ready means of analyzing semiology with concomitant (causal) brain activity using video-EEG or SEEG; this is in contrast to non-epileptic seizure disorders ${ }^{102}$ and psychiatric disorders more generally ${ }^{103}$. Electroclinical data can be complemented with other sources including functional imaging studies in the ictal ${ }^{104,105}$ and/or interictal period ${ }^{67}$. An advantage of using functional imaging is its whole-brain approach, which can be used in a complementary way to other data, relevant for example to better understanding the role of basal ganglia and other subcortical structures in epilepsy and potentially in semiology production ${ }^{104-106}$. In fact 
"interictal semiology" (e.g. psychiatric ${ }^{107,108}$ and cognitive ${ }^{109}$ symptoms) could be an interesting line of study, the neural correlates of which may prove to be related to epilepsy $\operatorname{organization}^{108}$ and even ictal semiology ${ }^{107}$. Mapping approaches using intracerebral data to study cortical correlates of cognition and emotion could also help to advance knowledge of the neural correlates of higher brain functions ${ }^{110}$.

For future advances in semiological analysis, harnessing technological advances in quantifying semiology via video analysis seems of interest ${ }^{111}$, for example facial expression ${ }^{112}$ and body/limb movements ${ }^{91,113}$. These methods require expert supervision and/or specific technical capacities and are not yet widely used but may become more available if they prove effective. Refining current use of autonomic recording during seizures (e.g. electrocardiographic analysis, respiration, electrodermal response), possibly including use of wearable devices ${ }^{114}$, could also be informative. Modelization approaches are of interest since they can potentially overcome the problem of spatial sampling ${ }^{49}$; such models would benefit from being able to incorporate semiological data, but present approaches do not yet include these because of the challenges of sufficiently simplifying and quantifying complex behavioral data.

Analyzing larger case series seems important for achieving higher power in demonstrating differences between different semiological subtypes and their brain correlates, bearing in mind that most semiological series in the SEEG literature to date report on around 20-50 subjects, often less. Beyond encouraging more multi-center collaboration, potential use of larger scale international databases, adapted to a multi-scale approach ${ }^{115}$ could be of future interest. For this to occur, various practical issues would need to be resolved, including how to protect patient confidentiality. In addition, analyzing large amounts of video data is 
onerous and would ideally be supplemented by some automated approaches if this becomes more reliable.

\section{Evolving concepts and therapeutic implications}

An important element for making progress in elucidating neural correlates of semiology may be evolution of current concepts. As discussed earlier, the network model of epilepsy appears better suited than the focus model to understanding relations between electrical seizure organization and clinical expression. Since thinking about epilepsy in terms of network theory represents a paradigm shift, it may be useful to reconsider how we use some current language. An example is the term "symptomatogenic zone", used by many clinicians in a presurgical context, which in fact proves not to be compatible with the network model of seizures and semiology: we can recall that the term was defined by Luders and collaborators as "the area of cortex that, when activated by an epileptiform discharge, produces the ictal symptoms" ${ }^{27}$. This appears imprecise in the light of the data discussed earlier, because not only spatial but also temporal features of discharge affect clinical expression; and not only cortical but also subcortical structures likely shape clinical expression. In addition, for some semiologic features (such as altered consciousness), the mechanism appears not to be activation but rather dysfunction or inhibition of cortical networks.

Semiology can teach us much more about epilepsy, and about the brain, than we currently know. Using behavioral data to drive research and improve understanding of the brainbehavior relationship may be pivotal in achieving neuroscientific progress more generally ${ }^{116}$. Better knowledge of the significance of semiologic substrates may help advance therapeutic 
McGonigal A, Bartolomei F, Chauvel P. On seizure semiology. Epilepsia. Published online July 2021

strategies especially from a neurosurgical point of view: understanding an individual patient's seizures as events that emerge from a dysfunctional brain network could allow multi-modal personalized treatment plans aimed at "taking the seizure network offline"117, encompassing tailored neuromodulation methods in some ${ }^{70}$, as well as physical disruption of key nodes in the network ${ }^{118}$ by resection or laser therapy for example where indicated. Future therapeutic approaches may even be directly driven by semiology in some cases, targeting specific disabling symptoms such as altered consciousness ${ }^{119}$. 
McGonigal A, Bartolomei F, Chauvel P. On seizure semiology. Epilepsia. Published online July 2021

Key points

- Neural mechanisms of semiology are poorly known, especially for complex ictal behaviors

- Network approaches are better suited than the focus model to investigating neural correlates of semiology

- In a network context, specific rhythmic interactions of activity between structures and not just anatomic localization appear important

- Methodological challenges of investigating semiology are significant, including observer bias and categorization

- Better knowledge of neural substrates of semiology could help lead to therapeutic advances aimed at network modification 
McGonigal A, Bartolomei F, Chauvel P. On seizure semiology. Epilepsia. Published online July 2021

\section{Acknowledgements}

The authors thank Dr Stéphane Dufau, CNRS for help with preparing the figure.

\section{Conflicts of interest}

None of the authors has any interests to disclose.

\section{Ethical Publication Statement}

We confirm that we have read the Journal's position on issues involved in ethical publication and affirm that this report is consistent with those guidelines.

\section{Legends to tables}

Table 1. Examples of studies examining semiology in conjunction with signal analysis of SEEG (temporal aspects of seizure organization)

Table 2. Examples of SEEG electroclinical studies examining semiology in conjunction with sublobar organization (anatomic correlates)

Table 3. Methodological challenges of using semiology as a data source in clinical research 
McGonigal A, Bartolomei F, Chauvel P. On seizure semiology. Epilepsia. Published online July 2021

Table 1. Examples of studies examining semiology in conjunction with signal analysis of SEEG (temporal aspects of seizure organization)

Table updated from ref. ${ }^{16}$

\begin{tabular}{|c|c|c|c|c|c|c|c|}
\hline Authors & Year & $\begin{array}{l}\text { Semiological } \\
\text { pattern }\end{array}$ & $\begin{array}{l}\text { Epilepsy } \\
\text { localization }\end{array}$ & $\begin{array}{l}\text { Number of } \\
\text { subjects }\end{array}$ & Main anatomical structures & Control group & $\begin{array}{l}\text { Signal analysis of SEEG during period of semiological } \\
\text { expression }\end{array}$ \\
\hline Bartolomei et al. .86 & 2002 & Humming & Temporal lobe & 3 & $\begin{array}{l}\text { Superior temporal gyrus } \\
\text { (STG), prefrontal cortex }\end{array}$ & No & $\begin{array}{l}\text { Rhythmic discharge over STG (6Hz or } 15 \mathrm{~Hz}) \text {. Increased } \\
\text { coherence between STG and prefrontal cortex }\end{array}$ \\
\hline Bartolomei et al..$^{90}$ & 2005 & Fear behavior & Prefrontal cortex & 3 & $\begin{array}{l}\text { Ventromesial orbitofrontal } \\
\text { cortex, anterior cingulate, } \\
\text { amygdala (limbic system) }\end{array}$ & No & $\begin{array}{l}\text { Sudden loss of synchrony between orbitofrontal cortex and } \\
\text { amygdala at seizure onset/clinical onset }\end{array}$ \\
\hline Arthuis et al. ${ }^{11}$ & 2009 & $\begin{array}{l}\text { Impaired } \\
\text { consciousness }\end{array}$ & Temporal lobe & 12 & $\begin{array}{l}\text { Temporal structures, parietal } \\
\text { lobe, thalamus }\end{array}$ & $\begin{array}{l}\text { Compared at group } \\
\text { level according to } \\
\text { degree of altered } \\
\text { consciousness }\end{array}$ & $\begin{array}{l}\text { Excessive synchrony (h2), i.e. functional coupling, between } \\
\text { temporal and extra-temporal structures, notably parietal } \\
\text { cortex and thalamus in seizures with marked alteration of } \\
\text { consciousness }\end{array}$ \\
\hline Lambert et al. .88 & 2012 & $\begin{array}{l}\text { Impaired } \\
\text { consciousness }\end{array}$ & Parietal lobe & 10 & $\begin{array}{l}\text { Superior and inferior parietal } \\
\text { lobules, precuneus, parietal } \\
\text { operculum, supplementary } \\
\text { motor area }\end{array}$ & $\begin{array}{l}\text { Compared at group } \\
\text { level according to } \\
\text { degree of altered } \\
\text { consciousness }\end{array}$ & $\begin{array}{l}\text { Increased synchrony was associated with progressively } \\
\text { greater degrees of altered responsiveness at subgroup level. } \\
\text { A statistically significant nonlinear relationship was found } \\
\text { between }\end{array}$ \\
\hline
\end{tabular}


McGonigal A, Bartolomei F, Chauvel P. On seizure semiology. Epilepsia. Published online July 2021

\begin{tabular}{|c|c|c|c|c|c|c|c|}
\hline & & & & & & & $\begin{array}{l}\text { h2 values and degree of alteration of consciousness, } \\
\text { suggesting a threshold effect. Cf Arthuis et al, 200971. }\end{array}$ \\
\hline Bonini et al89 & 2016 & $\begin{array}{l}\text { Impaired } \\
\text { consciousness }\end{array}$ & Frontal lobe & 24 & $\begin{array}{l}\text { Internal and external } \\
\text { prefrontal cortex, premotor } \\
\text { cortex, parietal cortex }\end{array}$ & $\begin{array}{l}\text { Compared at group } \\
\text { level according to } \\
\text { degree of altered } \\
\text { consciousness }\end{array}$ & $\begin{array}{l}\text { At subgroup level, seizures characterized by marked altered } \\
\text { consciousness were associated with highest levels of } \\
\text { synchrony. Significant correlation was found between } \\
\text { consciousness scores and correlation values (h2) of the } \\
\text { prefrontal and the parietal region but not with the premotor } \\
\text { cortex. Cf Arthuis et al, } 2009^{71} \text { and Lambert et al88. }\end{array}$ \\
\hline Hagiwara et al ${ }^{120}$ & 2017 & Motor signs & Insula & 5 & $\begin{array}{l}\text { Insula, premotor and } \\
\text { prefrontal cortex }\end{array}$ & $\begin{array}{l}\text { Seizures } \\
\text { with/without } \\
\text { "frontal semiology" } \\
\text { were compared }\end{array}$ & $\begin{array}{l}\text { Non-linear regression analysis was applied to insular seizures } \\
\text { with/without frontal presentation } \\
\text { The three patients with frontal semiology showed strong } \\
\text { couplings with the mesial frontal as well as cingulate regions, } \\
\text { including the } \\
\text { medial orbitofrontal cortex, pre-SMA/SMA, and the anterior } \\
\text { to posterior cingulate. The two patients with } \\
\text { the insular semiology only showed couplings between the } \\
\text { insula and cingulate regions. }\end{array}$ \\
\hline Bartolomei et al..$^{95}$ & 2017 & Ictal aggression & Temporal lobe & 1 & $\begin{array}{l}\text { Bilateral temporal and frontal } \\
\text { structures }\end{array}$ & No & $\begin{array}{l}\text { Aggression occurred in the last part of the seizure, during } \\
\text { which period functional connectivity study ( } h^{2} \text { estimation of }\end{array}$ \\
\hline
\end{tabular}


McGonigal A, Bartolomei F, Chauvel P. On seizure semiology. Epilepsia. Published online July 2021

\begin{tabular}{|c|c|c|c|c|c|c|c|}
\hline & & & & & & & $\begin{array}{l}\text { interdependencies) showed bilateral massive } \\
\text { hypersynchronization between frontal and temporal regions }\end{array}$ \\
\hline Aupy et al87. & 2018 & $\begin{array}{l}\text { Oro-alimentary } \\
\text { automatisms } \\
\text { (OAA) }\end{array}$ & Temporal lobe & 15 & $\begin{array}{l}\text { Medial basal temporal lobe, } \\
\text { opercular cortex }\end{array}$ & $\begin{array}{l}\text { 2/15 patients had } \\
\text { seizures compared } \\
\text { with and without } \\
\text { OAA }\end{array}$ & $\begin{array}{l}\text { Increased coherence occurred between medio-basal } \\
\text { temporal structures and insulo-opercular cortex prior to } \\
\text { onset of rhythmic chewing movements }\end{array}$ \\
\hline Roux et a| $\left.\right|^{121}$ & 2019 & Ictal coughing & Temporal lobe & 1 & Mesial temporal structures & No & $\begin{array}{l}\text { Functional connectivity study }\left(\mathrm{h}^{2} \text { estimation of }\right. \\
\text { interdependencies) showed that during coughing, a network } \\
\text { of cortical and subcortical regions was involved, particularly } \\
\text { the perisylvian cortices and the caudate nucleus. }\end{array}$ \\
\hline Zalta et al76 & 2020 & $\begin{array}{l}\text { Antero-posterior } \\
\text { rocking }\end{array}$ & Frontal lobe & 1 & Prefrontal cortex & $\begin{array}{l}\text { Compared with non- } \\
\text { rocking seizures in } \\
\text { same patient }\end{array}$ & $\begin{array}{l}\text { Delta range rhythmic body rocking was associated with cortical } \\
\text { delta oscillatory activity and phase-coupled high-gamma energy }\end{array}$ \\
\hline
\end{tabular}


McGonigal A, Bartolomei F, Chauvel P. On seizure semiology. Epilepsia. Published online July 2021

Table 2: Examples of SEEG electroclinical studies examining semiology in conjunction with sublobar organization (anatomic correlates)

Table updated from ref. ${ }^{16}$

\begin{tabular}{|c|c|c|c|c|c|}
\hline Authors & Year & $\begin{array}{l}\text { Brain region } \\
\text { involved in } \\
\text { seizure } \\
\text { organization }\end{array}$ & $\begin{array}{l}\mathrm{N}^{\circ} \text { of } \\
\text { subjects }\end{array}$ & $\begin{array}{l}\mathrm{N}^{\circ} \text { of } \\
\text { seizures }\end{array}$ & Main findings \\
\hline Maillard et al. ${ }^{122}$ & 2004 & Temporal lobe & 55 & 187 & $\begin{array}{l}\text { Subgroups defined by clinical and SEEG features: mesial type (initial epigastric sensation and delayed appearance of oro-alimentary } \\
\text { and gestural automatisms as well as later (if any) altered consciousness); lateral type (early auditory illusions or hallucinations, earlier } \\
\text { altered consciousness, more frequent generalization); mesial-lateral type (initial epigastric sensation and early altered contact, long } \\
\text { seizure duration). This study built on observations from SEEG signal analysis work }{ }^{31} \text {. }\end{array}$ \\
\hline Bartolomei et al. ${ }^{123}$ & 2011 & Parietal lobe & 17 & 34 & $\begin{array}{l}\text { Neural network patterns with respect to seizure semiology, }{ }^{123} \text { applying the previously developed Epileptogenicity Index }(E I)^{124} \text { to } \\
\text { quantify fast discharge at seizure onset. Seizures predominantly arising from superior parietal lobule were often associated with } \\
\text { vestibular symptoms, whereas hyperkinetic motor behavior was associated with inferior parietal involvement. }\end{array}$ \\
\hline $\begin{array}{l}\text { Bonini, McGonigal et } \\
\text { al. }^{74}\end{array}$ & 2014 & Frontal lobe & 54 & 374 & $\begin{array}{l}\text { Using automated cluster analysis of clinical signs and of brain areas involved in seizure onset and early propagation, correlation was } \\
\text { seen along a rostro-caudal gradient from frontal pole to precentral cortex. Four groups of patients were described, proceeding from } \\
\text { central cortex and moving rostrally: Group } 1 \text { (elementary motor signs, no gestural motor behavior); Group } 2 \text { (association of } \\
\text { elementary motor signs and gestural motor behavior, often with mainly proximal tonic signs and facial contraction; Group } 3 \text { (no }\end{array}$ \\
\hline
\end{tabular}


McGonigal A, Bartolomei F, Chauvel P. On seizure semiology. Epilepsia. Published online July 2021

\begin{tabular}{|c|c|c|c|c|c|}
\hline & & & & & $\begin{array}{l}\text { elementary motor signs, gestural motor behavior often with a distal expression, which could have an integrated appearance); Group } 4 \\
\text { (no elementary motor signs; gestural motor behavior that occurred in a context of emotional expression, most often fearful, with an } \\
\text { integrated appearance). }\end{array}$ \\
\hline Marchi et al. ${ }^{125}$ & 2016 & Occipital lobe & 29 & 194 & $\begin{array}{l}\text { Used the El|124 quantification method. Widespread organization of the EZ was typical, with temporal and/or parietal cortex quite } \\
\text { commonly being involved ("occipital-plus epilepsy"). Altered conscious level was more common when onset involved widespread } \\
\text { posterior neocortex; automatic motor behavior and/or verbal automatisms more often seen with occipito-temporal organization. }\end{array}$ \\
\hline Wang et al. ${ }^{57}$ & 2020 & $\begin{array}{l}\text { Insulo- } \\
\text { opercular } \\
\text { cortex }\end{array}$ & 37 & 310 & $\begin{array}{l}\text { Used automated cluster analysis of clinical signs and of brain areas, based on a novel methodology of brain parcellation including } \\
\text { connectivity parameters (Brainnetome). Four main semiologic subgroups of insulo-opercular seizures were identified, organized along } \\
\text { an anteroventral to posterodorsal axis. Semiology, particularly sensory symptoms but also motor signs, significantly correlated with } \\
\text { insulo-opercular subregion localization. }\end{array}$ \\
\hline Singh et al. 55 & 2020 & Insula & 12 & 25 & $\begin{array}{l}\text { Review of semiology defined clinical groups, agglomerative cluster and principal component analysis of semiological features was } \\
\text { performed in twelve patients with "pure" insula epilepsy }(n=9) \text { or insular and only deepest opercular involvement }(n=3) \text { Quantitative } \\
\text { epileptogenicity, intra-insular and extra-insular propagation were computed via time frequency analysis and epileptogenicity mapping. } \\
\text { The largest principal component separated anterior insula manifestations including early hypermotor signs, early recovery and no aura } \\
\text { from posterior insula features of early dystonia, early tonic motor features and sensorimotor aura. }\end{array}$ \\
\hline Peltola et al. ${ }^{56}$ & 2020 & Insula & 11 & 79 & $\begin{array}{l}\text { Only pure insular epilepsies were selected. Epileptogenicity index was used to define seizure onset zone and seizure discharge type } \\
\text { was assessed. Hyperkinetic signs, speech modifications, and viscerosensory symptoms were related to an anterior insular seizure- }\end{array}$ \\
\hline
\end{tabular}


McGonigal A, Bartolomei F, Chauvel P. On seizure semiology. Epilepsia. Published online July 2021

\begin{tabular}{|l|l|l|l|l|l|}
\hline & & & & $\begin{array}{l}\text { onset zone. Pain, asymmetric tonic, focal clonic, and tonic symptoms were more frequent in patients with a posterior insular seizure } \\
\text { onset. }\end{array}$ \\
\hline Machado et al.77 & 2020 & Prefrontal & 31 & 51 & $\begin{array}{l}\text { Investigation of dorsolateral prefrontal cortex (DLPFC), ventrolateral prefrontal cortex (VLPFC), dorsomedial prefrontal cortex } \\
\text { (DMPFC), ventromedial prefrontal cortex (VMPFC), and orbitofrontal cortex (OFC). The seizure onset zone (SOZ) was determined from } \\
\text { one or two seizures in each patient, using the epileptogenicity index (EI) method. Note that this methodology differed from that of } \\
\text { Bonini et al.74, as early spread was not considered. Optimal clustering was } 4 \text { subgroups of prefrontal seizures: a "pure DLPF" group, a } \\
\text { "pure VMPF" group, a "pure OFC" group, and a "global prefrontal" group. No significant difference was found in the distribution of } \\
\text { ictal signs between the different groups. }\end{array}$ \\
\hline
\end{tabular}


McGonigal A, Bartolomei F, Chauvel P. On seizure semiology. Epilepsia. Published online July 2021

Table 3. Methodological challenges of using semiology as a data source in clinical research

\begin{tabular}{|c|c|c|}
\hline Methodological issues & Challenges & Examples of main issues \\
\hline \multirow[t]{3}{*}{ Semiological analysis } & Recording conditions & $\begin{array}{l}\text { - Insufficient ictal testing (consciousness, } \\
\text { language) } \\
\text { - Patient covered by bedsheet or off camera } \\
\text { - Poor lighting; low camera resolution }\end{array}$ \\
\hline & Observer bias & $\begin{array}{l}\text { - Seizures with emotional behavior, especially } \\
\text { facial expression (may be more difficult to } \\
\text { - } \quad \text { "Unnatural” patterns of motor semiology may } \\
\text { be more difficult to observe and describe } \\
\text { Seizure semiology that is difficult to perceive, } \\
\text { because of few signs or because of multiple } \\
\text { signs evolving very rapidly } \\
\text { Well-known signs versus rarely seen signs or } \\
\text { - } \quad \text { observer's level of experience and expertise } \\
\text { Inter-observer agreement }\end{array}$ \\
\hline & Description of semiology & $\begin{array}{l}\text { - Seizures with a complex and/or idiosyncratic } \\
\text { appearance } \\
\text { - Signs of which the significance remains } \\
\text { - Anknown (risk of under-reporting) } \\
\text { - } \text { - } \text { - Noutomatiguity of some current terms, e.g. "hyperkinetic seizure" } \\
\text { terms of localization of some current categories in }\end{array}$ \\
\hline
\end{tabular}




\begin{tabular}{|c|c|c|}
\hline & & $\begin{array}{l}\text { - How to quantify semiology? E.g. intensity of } \\
\text { emotional signs, degree of alteration of } \\
\text { consciousness }\end{array}$ \\
\hline & Numbers of data & $\begin{array}{l}\text { - Individual patient: compare seizures with and } \\
\text { - } \quad \text { sithout a specific sign? } \\
\text { - Should versus large case series } \\
\text { - Shtrol group be used? }\end{array}$ \\
\hline SEEG data & Spatial sampling limitations & 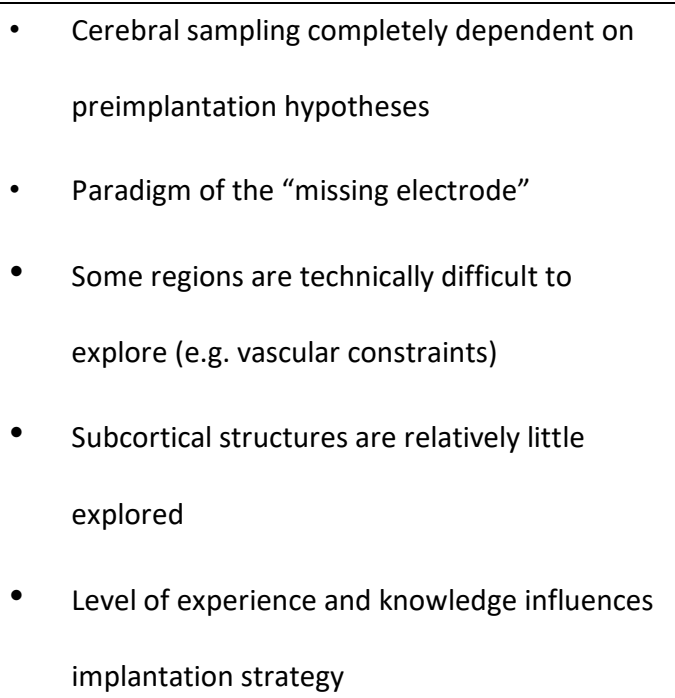 \\
\hline & Period of analysis of SEEG & $\begin{array}{l}\text { - } \quad \text { Choice of optimal time period? } \\
\text { - Seizure onset, early spread? What duration? } \\
\text { - Should period of analysis depend on signal, on } \\
\text { - How many seizures to ensure reproducibility of } \\
\text { pattern? }\end{array}$ \\
\hline & Signal analysis & $\begin{array}{l}\text { - Choice of method? } \\
\text { - } \quad \text { Quantification of fast versus slow activity at } \\
\text { - Connectivity measures }(\mathrm{H} 2) \\
\text { - } \quad \text { Phase lag coupling } \\
\text { - Coherence }\end{array}$ \\
\hline
\end{tabular}


McGonigal A, Bartolomei F, Chauvel P. On seizure semiology. Epilepsia. Published online July 2021

\begin{tabular}{|l|l|c|}
\hline Conceptual issues & $\begin{array}{l}\text { Neural network versus } \\
\text { focal/symptomatogenic zone } \\
\text { model }\end{array}$ & $\begin{array}{l}\text { Methodology of investigating mechanisms and } \\
\text { anatomic substrates will be shaped by }\end{array}$ \\
\cline { 2 - 3 } & Mainly cortical versus cortico- & Concepts of seizure localization and \\
subcortical view & semiological expression very influenced by \\
& level of expertise and experience in individual \\
& teams (inter-center variability) \\
\hline
\end{tabular}


1. Martinet L, Quain J. Manual of Pathology: Containing the Symptoms, Diagnosis, and Morbid Characters of Diseases; Together with an Exposition of the Different Methods of Examination, Applicable to Affections of the Head, Chest, \& Abdomen: W. Simpkin \& R. Marshall; 1829.

2. Mackenzie J. The theory of disturbed reflexes in the production of symptoms of disease British medical journal. 1921;1:147.

3. Engel J. Update on surgical treatment of the epilepsies: summary of the second international Palm Desert conference on the surgical treatment of the epilepsies (1992) Neurology. 1993;43:1612-1612.

4. Magiorkinis E, Sidiropoulou K, Diamantis A. Hallmarks in the history of epilepsy: epilepsy in antiquity Epilepsy \& Behavior. 2010;17:103-108.

5. Jackson JH. Selected Writings of John Hughlings Jackson: On Epilepsy and epileptiform convulsions. London: Hodder and Stoughton; 1931.

6. Penfield W, Gage L. Cerebral localization of epileptic manifestations Archives of Neurology \& Psychiatry. 1933;30:709-727.

7. Gastaut H, Broughton RJ. Epileptic seizures: clinical and electrographic features, diagnosis and treatment: Charles C. Thomas Publisher; 1972.

8. Bancaud J, Bonis A, Munari C, Szikla G, Chodkiewicz J, Talairach J. Localizing value of the clinical manifestations of the partial seizures. Advances in Stereotactic and Functional Neurosurgery 6: Springer; 1984. p. 7-15.

9. Bancaud J, Talairach J. La stéréo-électroencéphalographie dans l'épilepsie: informations neurophysiopathologiques apportées par l'investigation fonctionnelle stéreotaxique. Paris: Masson et Cie; 1965.

10. Gastaut H. Dictionary of epilepsy. 1973.

11. Berg AT, Berkovic SF, Brodie MJ, Buchhalter J, Cross JH, Van Emde Boas W, et al. Revised terminology and concepts for organization of seizures and epilepsies: report of the ILAE Commission on Classification and Terminology, 2005-2009 Epilepsia. 2010;51:676-685. 12. Fisher RS, Cross JH, French JA, Higurashi N, Hirsch E, Jansen FE, et al. Operational classification of seizure types by the International League Against Epilepsy: Position Paper of the ILAE Commission for Classification and Terminology Epilepsia. 2017;58:522-530.

13. Classification Co, Epilepsy TotILA. Proposal for revised clinical and electroencephalographic classification of epileptic seizures Epilepsia. 1981;22:489-501. 14. Chauvel P, Gonzalez-Martinez J, Bulacio J. Presurgical intracranial investigations in epilepsy surgery Handbook of clinical neurology. 2019;161:45-71.

15. Chauvel P. Contributions of Jean Talairach and Jean Bancaud to epilepsy surgery Epilepsy surgery 2nd ed Philadelphia (PA): Lippincott Williams \& Wilkins. 2001:35-41.

16. McGonigal A. Semiology and Epileptic Networks Neurosurgery Clinics. 2020.

17. Gastaut H. Clinical and electroencephalographical classification of epileptic seizures Epilepsia. 1970;11:102-112.

18. Lüders HO, Burgess R, Noachter S. Expanding the international classification of seizures to provide localization information NEUROLOGY-MINNEAPOLIS-. 1993;43:16501650. 
19. Lüders H, Acharya J, Baumgartner C, Benbadis S, Bleasel A, Burgess R, et al. Semiological Seizure Classification Epilepsia. 1998;39:1006-1013.

20. Lüders H, Akamatsu N, Amina S, Baumgartner C, Benbadis S, Bermeo-Ovalle A, et al. Critique of the 2017 epileptic seizure and epilepsy classifications Epilepsia. 2019;60:10321039.

21. Spencer SS. Neural networks in human epilepsy: evidence of and implications for treatment Epilepsia. 2002;43:219-227.

22. Kramer MA, Cash SS. Epilepsy as a disorder of cortical network organization The Neuroscientist. 2012;18:360-372.

23. Bartolomei F, Lagarde S, Wendling F, McGonigal A, Jirsa V, Guye M, et al. Defining epileptogenic networks: Contribution of SEEG and signal analysis Epilepsia. 2017.

24. Taylor J. Neural networks and the brain. Physics and Mathematics of the Nervous System: Springer; 1974. p. 230-253.

25. McNamara JO. Kindling: an animal model of complex partial epilepsy Annals of Neurology: Official Journal of the American Neurological Association and the Child Neurology Society. 1984;16:S72-S76.

26. Bancaud J, Brunet-Bourgin F, Chauvel P, Halgren E. Anatomical origin of déjà vu and vivid 'memories' in human temporal lobe epilepsy Brain. 1994;117 ( Pt 1):71-90.

27. Rosenow F, Lüders H. Presurgical evaluation of epilepsy Brain. 2001;124:1683-1700.

28. Chauvel P. The Epileptogenic Zone: A Critical Reconstruction. In: Schuele SU, editor. A Practical Approach to Stereo EEG. New York: Springer Publishing Company; 2020. p. 105120.

29. Munari C, Bancaud J. The role of stereo-electroencephalography (SEEG) in the evaluation of partial epileptic seizures. The Epilepsies London: Butterworth; 1985. p. 267306.

30. Wendling F, Bartolomei F, Bellanger JJ, Chauvel P. Interpretation of interdependencies in epileptic signals using a macroscopic physiological model of the EEG Clin Neurophysiol. 2001;112:1201-1218.

31. Bartolomei F, Wendling F, Vignal JP, Kochen S, Bellanger JJ, Badier JM, et al. Seizures of temporal lobe epilepsy: identification of subtypes by coherence analysis using stereoelectro-encephalography Clin Neurophysiol. 1999 Oct;110:1741-1754.

32. Wendling F, Chauvel P, Biraben A, Bartolomei F. From intracerebral EEG signals to brain connectivity: identification of epileptogenic networks in partial epilepsy Front Syst Neurosci. 2010;4:154.

33. Bartolomei F, Wendling F, Chauvel P. [The concept of an epileptogenic network in human partial epilepsies] Neurochirurgie. 2008;54:174-184.

34. Schulz R, Lüders H, Tuxhorn I, Ebner A, Holthausen H, Hoppe $M$, et al. Localization of epileptic auras induced on stimulation by subdural electrodes Epilepsia. 1997;38:1321-1329. 35. Wyllie E, Luders H, Morris HH, Lesser RP, Dinner DS. The lateralizing significance of versive head and eye movements during epileptic seizures Neurology. 1986;36:606-606.

36. Kotagal P, Lüders H, Morris H, Dinner D, Wyllie E, Godoy J, et al. Dystonic posturing in complex partial seizures of temporal lobe onset A new lateralizing sign Neurology. 1989;39:196-196.

37. Laskowitz DT, Sperling MR, French JA, O'Connor MJ. The syndrome of frontal lobe epilepsy: characteristics and surgical management Neurology. 1995;45:780-787. 
38. Gil-Nagel A, Risinger MW. Ictal semiology in hippocampal versus extrahippocampal temporal lobe epilepsy Brain: a journal of neurology. 1997;120:183-192.

39. Ficker DM, Cascino GD, Trenerry MR, Marsh WR. Lesional temporal lobe epilepsy: ictal semiology and operative outcome Journal of Epilepsy. 1997;10:298-302.

40. Jobst BC, Siegel AM, Thadani VM, Roberts DW, Rhodes HC, Williamson PD.

Intractable seizures of frontal lobe origin: clinical characteristics, localizing signs, and results of surgery Epilepsia. 2000;41:1139-1152.

41. Lüders H. Symptomatogenic areas and electrical cortical stimulation. . In: Luders HO, Noachtar S, editors. Epileptic seizures: pathophysiology and clinical semiology New York: Churchill Livingstone; 2000. p. 131-140.

42. Horsley V. Remarks on the surgery of the central nervous system British medical journal. 1890;2:1286.

43. Jobst BC, Cascino GD. Resective epilepsy surgery for drug-resistant focal epilepsy: a review Jama. 2015;313:285-293.

44. Hebbink J, Meijer H, Huiskamp G, van Gils S, Leijten F. Phenomenological network models: Lessons for epilepsy surgery Epilepsia. 2017;58:e147-e151.

45. Jehi L, Friedman D, Carlson C, Cascino G, Dewar S, Elger C, et al. The evolution of epilepsy surgery between 1991 and 2011 in nine major epilepsy centers across the United States, Germany, and Australia Epilepsia. 2015;56:1526-1533.

46. de Tisi J, Bell GS, Peacock JL, McEvoy AW, Harkness WF, Sander JW, et al. The longterm outcome of adult epilepsy surgery, patterns of seizure remission, and relapse: a cohort study The Lancet. 2011;378:1388-1395.

47. Clark A. An embodied cognitive science? Trends in cognitive sciences. 1999;3:345351.

48. Wendling F, Badier JM, Chauvel P, Coatrieux JL. A method to quantify invariant information in depth-recorded epileptic seizures Electroencephalogr Clin Neurophysiol. 1997 Jun;102:472-485.

49. Jirsa VK, Proix T, Perdikis D, Woodman MM, Wang H, Gonzalez-Martinez J, et al. The virtual epileptic patient: individualized whole-brain models of epilepsy spread Neuroimage. 2017;145:377-388.

50. Chauvel P, McGonigal A. Emergence of semiology in epileptic seizures Epilepsy Behav. 2014;38:94-103.

51. Richardson MP. Large scale brain models of epilepsy: dynamics meets connectomics Journal of Neurology, Neurosurgery \& Psychiatry. 2012;83:1238-1248.

52. Lytton WW, Arle J, Bobashev G, Ji S, Klassen TL, Marmarelis VZ, et al. Multiscale modeling in the clinic: diseases of the brain and nervous system Brain informatics. 2017 Dec;4:219-230.

53. Isnard J, Guénot M, Sindou M, Mauguiere F. Clinical Manifestations of Insular Lobe Seizures: A Stereo-electroencephalographic Study Epilepsia. 2004;45:1079-1090.

54. Ostrowsky K, Isnard J, Ryvlin P, Guénot M, Fischer C, Mauguière F. Functional mapping of the insular cortex: clinical implication in temporal lobe epilepsy Epilepsia. 2000;41:681-686.

55. Singh R, Principe A, Tadel F, Hoffmann D, Chabardes S, Minotti L, et al. Mapping the insula with stereo-electroencephalography: The emergence of semiology in insula lobe seizures Annals of Neurology. 2020;88:477-488. 
56. Peltola ME, Trébuchon A, Lagarde S, Scavarda D, Carron R, Metsähonkala L, et al. Anatomoelectroclinical features of SEEG-confirmed pure insular-onset epilepsy Epilepsy \& Behavior. 2020;105:106964.

57. Wang H, McGonigal A, Zhang K, Guo Q, Zhang B, Wang X, et al. Semiologic subgroups of insulo-opercular seizures based on connectional architecture atlas Epilepsia. 2020.

58. Cardinale $F$, Rizzi $M$, Vignati $E$, Cossu $M$, Castana $L$, d'Orio $P$, et al.

Stereoelectroencephalography: retrospective analysis of 742 procedures in a single centre Brain. 2019;142:2688-2704.

59. Bartolomei F, Barbeau EJ, Nguyen T, McGonigal A, Regis J, Chauvel P, et al. Rhinalhippocampal interactions during deja vu Clinical Neurophysiology. 2012;123:489-495.

Article

60. Perrone-Bertolotti M, Alexandre S, Jobb AS, De Palma L, Baciu M, Mairesse MP, et al. Probabilistic mapping of language networks from high frequency activity induced by direct electrical stimulation Human brain mapping. 2020;41:4113-4126.

61. Maillard L, Gavaret M, Régis J, Wendling F, Bartolomei F. Fast epileptic discharges associated with ictal negative motor phenomena Clinical Neurophysiology. 2014;125:23442348.

62. Talairach J, Bancaud J, Geier S, Bordas-Ferrer M, Bonis A, Szikla G, et al. The cingulate gyrus and human behaviour Electroencephalogr Clin Neurophysiol. 1973;34:45-52.

63. Caruana F, Gerbella M, Avanzini P, Gozzo F, Pelliccia V, Mai R, et al. Motor and emotional behaviours elicited by electrical stimulation of the human cingulate cortex Brain. 2018;141:3035-3051.

64. Engel J. Can we replace the terms "focal" and "generalized" Generalized seizures: from clinical phenomenology to understanding system and networks (Hirsch $E$, Andermann F, Chauvel P, Engel J, Lopes da Silva F, Luders H, eds). 2006:305-325.

65. Norden $A D$, Blumenfeld $H$. The role of subcortical structures in human epilepsy Epilepsy \& Behavior. 2002;3:219-231.

66. Englot DJ, Yang L, Hamid H, Danielson N, Bai X, Marfeo A, et al. Impaired consciousness in temporal lobe seizures: role of cortical slow activity Brain. 2010;133:37643777.

67. Guedj E, McGonigal A, Vaugier L, Mundler O, Bartolomei F. Metabolic brain PET pattern underlying hyperkinetic seizures Epilepsy Research. 2012 Sep;101:237-245. Article 68. Vercueil L, Hirsch E. Seizures and the basal ganglia: a review of the clinical data Epileptic Disorders. 2002;4:47-54.

69. Pizzo F, Roehri N, Giusiano B, Lagarde S, Carron R, Scavarda D, et al. The Ictal Signature of Thalamus and Basal Ganglia in Focal Epilepsy: A SEEG Study Neurology. 2020;96:e280-e293.

70. Aupy J, Wendling F, Taylor K, Bulacio J, Gonzalez-Martinez J, Chauvel P. Corticostriatal synchronization in human focal seizures Brain. 2019;142:1282-1295.

71. Arthuis M, Valton L, Régis J, Chauvel P, Wendling F, Naccache L, et al. Impaired consciousness during temporal lobe seizures is related to increased long-distance corticalsubcortical synchronization Brain. 2009;132:2091-2101.

72. Mesulam M. The evolving landscape of human cortical connectivity: facts and inferences Neuroimage. 2012;62:2182-2189. 
73. Fayerstein J, McGonigal A, Pizzo F, Bonini F, Lagarde S, Braquet A, et al. Quantitative analysis of hyperkinetic seizures and correlation with seizure onset zone Epilepsia. 2020;61:1019-1026.

74. Bonini F, McGonigal A, Trébuchon A, Gavaret M, Bartolomei F, Giusiano B, et al. Frontal lobe seizures: From clinical semiology to localization Epilepsia. 2014;55.2 264-277. 75. Badre D, D'Esposito M. Is the rostro-caudal axis of the frontal lobe hierarchical? Nat Rev Neurosci. 2009;10:659-669.

76. Zalta A, Hou J-C, Thonnat M, Bartolomei F, Morillon B, McGonigal A. Neural correlates of rhythmic rocking in prefrontal seizures Neurophysiologie Clinique. 2020;50:331-338.

77. Machado S, Bonini F, McGonigal A, Singh R, Carron R, Scavarda D, et al. Prefrontal seizure classification based on stereo-EEG quantification and automatic clustering Epilepsy \& Behavior. 2020;112:107436.

78. Grillner S. The motor infrastructure: from ion channels to neuronal networks Nature reviews Neuroscience. 2003;4:573.

79. Adolphs R, Anderson DJ. The neuroscience of emotion: A new synthesis: Princeton University Press; 2018.

80. Koch C, Massimini M, Boly M, Tononi G. Neural correlates of consciousness: progress and problems Nature Reviews Neuroscience. 2016;17:307-321.

81. Gibbs SA, Proserpio P, Terzaghi M, Pigorini A, Sarasso S, Russo GL, et al. Sleep-related epileptic behaviors and non-REM-related parasomnias: insights from stereo-EEG Sleep medicine reviews. 2016;25:4-20.

82. Graybiel AM. Habits, rituals, and the evaluative brain Annu Rev Neurosci. 2008;31:359-387.

83. McGonigal A, Chauvel P. Prefrontal Seizures Manifesting as Motor Stereotypies Movement Disorders. 2014;29:1181-1185. Article

84. Bartolomei F, Guye M, Wendling F. Abnormal binding and disruption in large scale networks involved in human partial seizures EPJ Nonlinear Biomedical Physics. 2013;1:1-16. 85. Barbeau E, Wendling F, Régis J, Duncan R, Poncet $M$, Chauvel $P$, et al. Recollection of vivid memories after perirhinal region stimulations: synchronization in the theta range of spatially distributed brain areas Neuropsychologia. 2005;43:1329-1337.

86. Bartolomei F, Wendling F, Vignal JP, Chauvel P, Liégeois-Chauvel C. Neural networks underlying epileptic humming Epilepsia. 2002;43:1001-1012.

87. Aupy J, Noviawaty I, Krishnan B, Suwankpakdee P, Bulacio J, Gonzalez-Martinez J, et al. Insulo-opercular cortex generates oroalimentary automatisms in temporal seizures Epilepsia. 2018;59:583-594.

88. Lambert I, Arthuis M, McGonigal A, Wendling F, Bartolomei F. Alteration of global workspace during loss of consciousness: a study of parietal seizures Epilepsia. 2012;53:21042110.

89. Bonini F, Lambert I, Wendling F, McGonigal A, Bartolomei F. Altered synchrony and loss of consciousness during frontal lobe seizures Clinical Neurophysiology. 2016;127:11701175.

90. Bartolomei F, Trébuchon A, Gavaret M, Régis J, Wendling F, Chauvel P. Acute alteration of emotional behaviour in epileptic seizures is related to transient desynchrony in emotion-regulation networks Clin Neurophysiol. 2005;116:2473-2479. 
91. Hou J-C, Thonnat M, Huys R, Bartolomei F, McGonigal A. Rhythmic rocking stereotypies in frontal lobe seizures: A quantified video study Neurophysiologie Clinique. 2020.

92. Tassinari CA, Rubboli G, Gardella E, Cantalupo G, Calandra-Buonaura G, Vedovello M, et al. Central pattern generators for a common semiology in fronto-limbic seizures and in parasomnias. A neuroethologic approach Neurol Sci. 2005;26 Suppl 3:s225-232.

93. Gardella E, Rubboli G, Francione S, Tassi L, Lo Russo G, Grillner S, et al. Seizurerelated automatic locomotion triggered by intracerebral electrical stimulation Epileptic Disord. 2008 Dec;10:247-252.

94. Tassinari CA, Cantalupo G, Högl B, Cortelli P, Tassi L, Francione S, et al. Neuroethological approach to frontolimbic epileptic seizures and parasomnias: The same central pattern generators for the same behaviours Rev Neurol (Paris). 2009;165:762-768. 95. Bartolomei F, Lagarde S, Lambert I, Trébuchon A, Villalon SM, McGonigal A, et al. Brain connectivity changes during ictal aggression (a strangulation attempt) Epileptic Disorders. 2017;19:367-373.

96. McGonigal A, Lagarde S, Trébuchon-Dafonseca A, Roehri N, Bartolomei F. Early onset motor semiology in seizures triggered by cortical stimulation during SEEG Epilepsy \& Behavior. 2018;88:262-267.

97. Rugg-Gunn F, Harrison N, Duncan J. Evaluation of the accuracy of seizure descriptions by the relatives of patients with epilepsy Epilepsy Research. 2001;43:193-199. 98. Beniczky S, Neufeld M, Diehl B, Dobesberger J, Trinka E, Mameniskiene R, et al. Testing patients during seizures: A European consensus procedure developed by a joint taskforce of the ILAE-Commission on European Affairs and the European Epilepsy Monitoring Unit Association Epilepsia. 2016;57:1363-1368.

99. Marashly A, Ewida A, Agarwal R, Younes K, Lüders HO. Ictal motor sequences: lateralization and localization values Epilepsia. 2016;57:369-375.

100. Seneviratne U, Rajendran D, Brusco M, Phan TG. How good are we at diagnosing seizures based on semiology? Epilepsia. 2012;53:e63-e66.

101. Blume WT, Lüders HO, Mizrahi E, Tassinari C, van Emde Boas W, Engel J. Glossary of descriptive terminology for ictal semiology: report of the ILAE task force on classification and terminology Epilepsia. 2001;42:1212-1218.

102. Reuber M, Brown RJ. Understanding psychogenic nonepileptic seizuresphenomenology, semiology and the integrative cognitive model Seizure. 2017;44:199-205. 103. Micoulaud-Franchi JA, Quiles C, Batail JM, Lancon C, Masson M, Dumas G, et al. Making psychiatric semiology great again: A semiologic, not nosologic challenge L'Encephale. 2018.

104. Wong CH, Mohamed A, Larcos G, McCredie R, Somerville E, Bleasel A. Brain activation patterns of versive, hypermotor, and bilateral asymmetric tonic seizures Epilepsia. 2010;51:2131-2139.

105. Kheder A, Thome U, Aung T, Krishnan B, Alexopoulos A, Wu G, et al. Investigation of networks underlying hyperkinetic seizures utilizing ictal SPECT Neurology. 2020;95:e637e642.

106. Newton MR, Berkovic SF, Austin M, Reutens DC, McKay W, Bladin PF. Dystonia, clinical lateralization, and regional blood flow changes in temporal lobe seizures Neurology. 1992;42:371-371. 
107. Trebuchon A, Bartolomei F, McGonigal A, Laguitton V, Chauvel P. Reversible antisocial behavior in ventromedial prefrontal lobe epilepsy Epilepsy \& Behavior. 2013. 108. Lothe A, Didelot A, Hammers A, Costes N, Saoud M, Gilliam F, et al. Comorbidity between temporal lobe epilepsy and depression: a [18 F] MPPF PET study Brain. 2008;131:2765-2782.

109. Englot DJ, Gonzalez HF, Reynolds BB, Konrad PE, Jacobs ML, Gore JC, et al. Relating structural and functional brainstem connectivity to disease measures in epilepsy Neurology. 2018;91:e67-e77.

110. Drane DL, Pedersen NP, Sabsevitz DS, Block C, Dickey AS, Alwaki A, et al. Cognitive and Emotional Mapping With SEEG Frontiers in Neurology. 2021;12:407.

111. Ahmedt-Aristizabal D, Fookes C, Dionisio S, Nguyen K, Cunha JPS, Sridharan S. Automated analysis of seizure semiology and brain electrical activity in presurgery evaluation of epilepsy: A focused survey Epilepsia. 2017;58:1817-1831.

112. Maurel P, McGonigal A, Keriven R, Chauvel P, editors. 3D model fitting for facial expression analysis under uncontrolled imaging conditions. 19th International Conference on Pattern Recognition; 2008.

113. Cunha JPS, Choupina HMP, Rocha AP, Fernandes JM, Achilles F, Loesch AM, et al. NeuroKinect: a novel low-cost 3Dvideo-EEG system for epileptic seizure motion quantification PloS one. 2016;11:e0145669.

114. Vieluf S, Reinsberger C, El Atrache R, Jackson M, Schubach S, Ufongene C, et al. Autonomic nervous system changes detected with peripheral sensors in the setting of epileptic seizures Scientific Reports. 2020;10:1-8.

115. Amunts K, Knoll AC, Lippert T, Pennartz CM, Ryvlin P, Destexhe A, et al. The Human Brain Project-Synergy between neuroscience, computing, informatics, and brain-inspired technologies PLoS biology. 2019;17:e3000344.

116. Krakauer JW, Ghazanfar AA, Gomez-Marin A, Maclver MA, Poeppel D. Neuroscience needs behavior: correcting a reductionist Bias Neuron. 2017;93:480-490.

117. Richardson RM. Decision Making in Epilepsy Surgery Neurosurgery Clinics. 2020;31:471-479.

118. Olmi S, Petkoski S, Guye M, Bartolomei F, Jirsa V. Controlling seizure propagation in large-scale brain networks PLoS computational biology. 2019;15:e1006805.

119. Kundishora AJ, Gummadavelli A, Ma C, Liu M, McCafferty C, Schiff ND, et al. Restoring conscious arousal during focal limbic seizures with deep brain stimulation Cerebral Cortex. 2017;27:1964-1975.

120. Hagiwara K, Jung J, Bouet R, Abdallah C, Guénot M, Garcia-Larrea L, et al. How can we explain the frontal presentation of insular lobe epilepsy? The impact of non-linear analysis of insular seizures Clinical Neurophysiology. 2017;128:780-791.

121. Roux A, Lagarde S, McGonigal A, Bartolomei F. Brain connectivity changes during ictal coughing Epileptic Disorders. 2019;21:353-357.

122. Maillard L, Vignal JP, Gavaret M, Guye M, Biraben A, McGonigal A, et al. Semiologic and electrophysiologic correlations in temporal lobe seizure subtypes Epilepsia.

2004;45:1590-1599.

123. Bartolomei F, Gavaret M, Hewett R, Valton L, Aubert S, Régis J, et al. Neural networks underlying parietal lobe seizures: a quantified study from intracerebral recordings Epilepsy Res. 2011;93:164-176. 
McGonigal A, Bartolomei F, Chauvel P. On seizure semiology. Epilepsia. Published online July 2021

124. Bartolomei F, Chauvel P, Wendling F. Epileptogenicity of brain structures in human temporal lobe epilepsy: a quantified study from intracerebral EEG Brain. 2008;131:18181830.

125. Marchi A, Bonini F, Lagarde S, McGonigal A, Gavaret M, Scavarda D, et al. Occipital and occipital "plus" epilepsies: A study of involved epileptogenic networks through SEEG quantification Epilepsy \& Behavior. 2016;62:104-114. 